\title{
Modified technique for left ventricular assist device insertion in the setting of apical calcification
}

\author{
Chirantan Mangukia, MCh, ${ }^{\mathrm{a}}$ Gengo Sunagawa, MD, ${ }^{\mathrm{a}}$ Stacey Brann, MD, ${ }^{\mathrm{a}}$ Eman Hamad, MD, ${ }^{\mathrm{b}}$ and \\ Yoshiya Toyoda, $\mathrm{MD},{ }^{\mathrm{a}}$ Philadelphia, $\mathrm{Pa}$
}

\footnotetext{
From the ${ }^{\mathrm{a} D i v i s i o n}$ of Cardiovascular Surgery, Department of Surgery, and ${ }^{\mathrm{b}}$ Division of Cardiology, Department of Medicine, Temple University Hospital, Philadelphia, Pa.

Disclosures: The authors reported no conflicts of interest.

The Journal policy requires editors and reviewers to disclose conflicts of interest and to decline handling or reviewing manuscripts for which they may have a conflict of interest. The editors and reviewers of this article have no conflicts of interest.

Received for publication April 6, 2021; accepted for publication April 7, 2021; available ahead of print April 13, 2021.

Address for reprints: Chirantan Mangukia, MCh, Division of Cardiovascular Surgery, Department of Surgery, Temple University Hospital, 3401 N Broad St, 3rd Floor, Parkinson Pavilion, Philadelphia, PA 19140 (E-mail: chirantan.mangukia@outlook.com)

JTCVS Techniques 2021;8:90-2

2666-2507

Copyright $(2021$ The Author(s). Published by Elsevier Inc. on behalf of The American Association for Thoracic Surgery. This is an open access article under the CC BY-NC-ND license (http://creativecommons.org/licenses/bync-nd/4.0/).

https://doi.org/10.1016/j.xjtc.2021.04.007
}

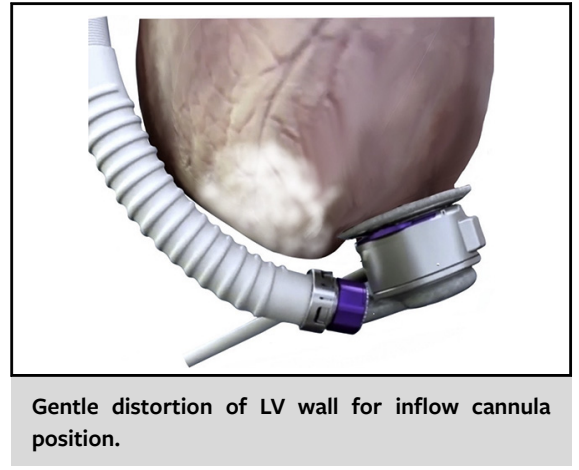

CENTRAL MESSAGE

Gentle distortion of the LV wall for inflow cannula position is well tolerated in patients with a calcified apex requiring anterolateral wall insertion of an LV assist device.

See Commentary on page 93.

\section{PRESENTATION}

A 53-year-old man, with a past medical history of nonischemic cardiomyopathy (ejection fraction, 15\%) secondary to chemoradiation for Hodgkin's lymphoma in 1991, multivessel coronary artery disease (after right coronary artery stent), and morbid obesity, developed acute cardiogenic shock due to refractory ventricular tachycardia despite having an implantable cardiodefibrillator.

Emergency peripheral venoarterial extracorporeal membrane oxygenation was initiated and an Impella $\mathrm{CP}$ (Abiomed Inc, Danvers, Mass) was inserted to decompress the left ventricle (LV). It was decided to implant a durable LV assist device (LVAD) as a bridge to transplantation. Preoperative imaging suggested extensive apical, inferior, lateral, and right ventricular wall endocardial calcification (Figure 1, $A$ and $B$ ). Transesophageal echocardiography (TEE) suggested an LV internal diastolic dimension of $75 \mathrm{~mm}$.

Because calcium was present extensively around the apex (marked area in Figure 1,C), there were only 2 options: complete debridement and reconstruction or choose an alternative site of device insertion. Given the severe cardiomegaly, calcification on inferior wall and a relatively small pericardial space, implanting a HeartMate 3 (Abbott Laboratories, Abbott Park, Ill) device on the diaphragmatic surface was deemed to be impractical. However, because of the large LV dimension, midanterolateral wall implantation of a HeartMate 3 device was technically feasible but direction of the inflow cannula toward the septum was a major long-term concern following LV size reduction due to remodeling.

Before initiating cardiopulmonary bypass, using TEE, we ensured a safe distance of $3 \mathrm{~cm}$ from the base of medial papillary muscle for the coring site (Figure $1, D$ ) on the midanterolateral wall. Close to the core, some endocardial calcification was removed to allow smooth insertion of anchoring sutures (Video 1). The surrounding LV wall was found to be moderately thin and compliant. A polytetrafluoroethylene doughnut was utilized for device ring implantation. Under TEE guidance, the device was manipulated to ensure that the inflow cannula was directed toward the mitral valve. This created a gentle distortion on LV apical and anterolateral wall, which was well tolerated without bleeding (Figure 2). We put 0-Prolene sutures 

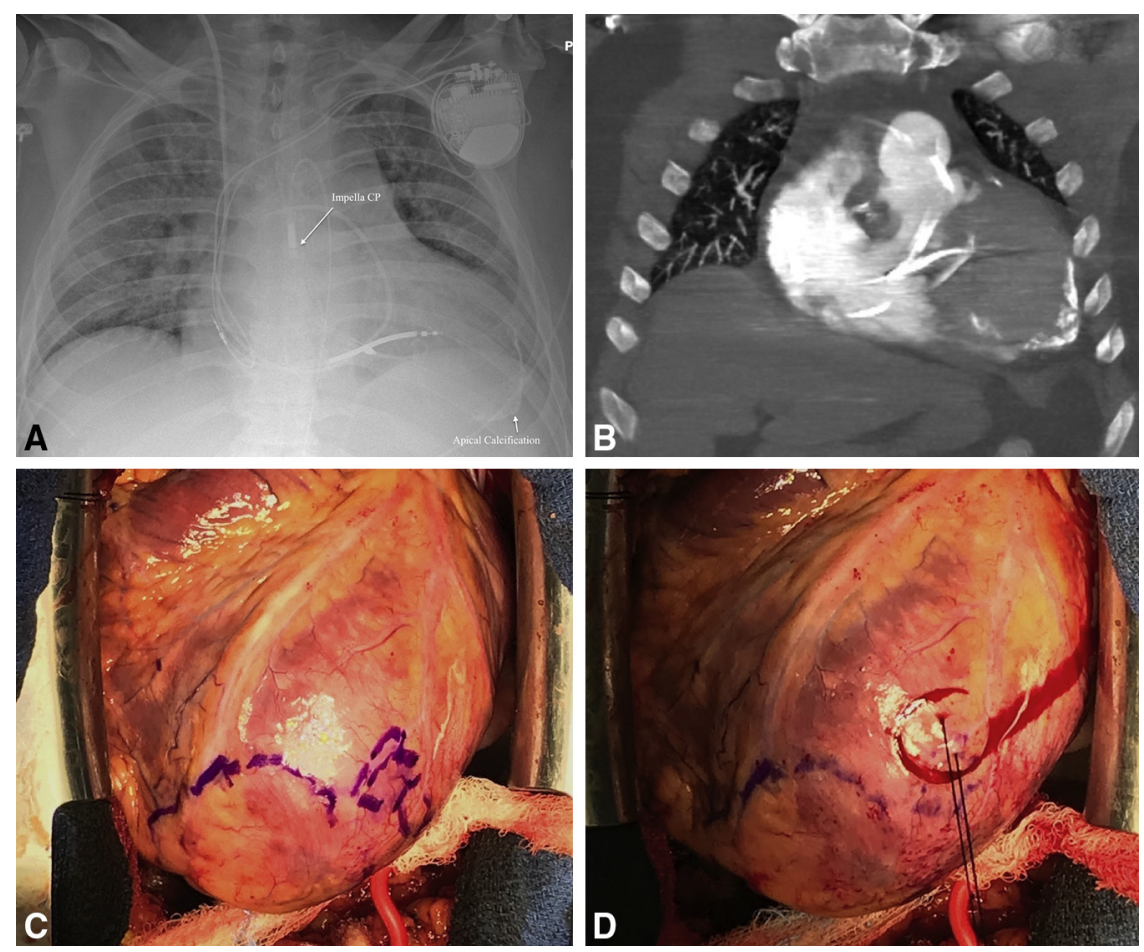

FIGURE 1. A, Chest radiograph suggesting apical calcification. B, Computed tomography of chest suggesting apical calcification. C, The perimeter of the calcified spot (blue marker line). D, Coring site.

around the junction of pump and outflow graft and anchored it to the rib and pericardial pocket to keep the cannula directed toward the mitral valve opening. Postbypass TEE suggested excellent cannula position (Video 1). TEE at 3 months suggested good cannula position (Video 1). At 9 months, the patient is doing well without

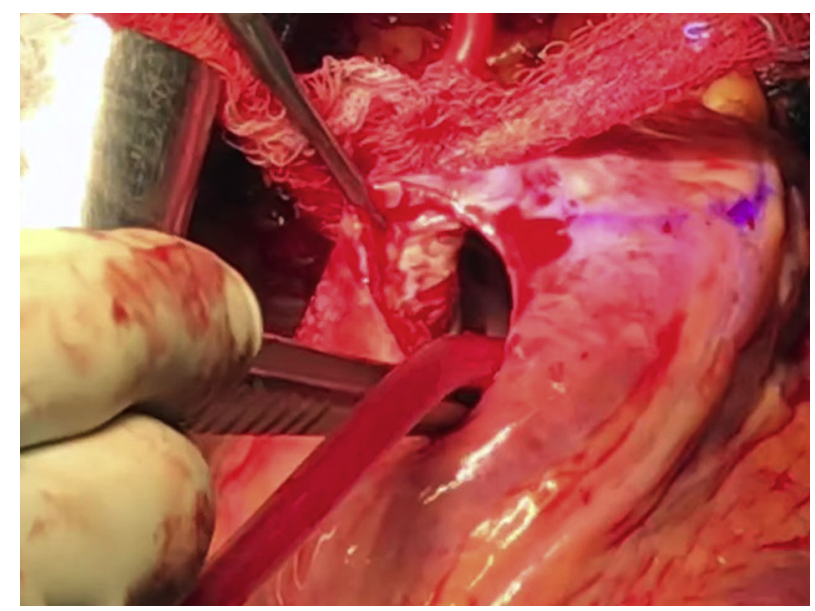

VIDEO 1. Video showing preimplant transesophageal echocardiography, subendocardial calcium removal after coring, postimplant transesophageal echocardiography, and transthoracic echocardiography at 3 months of follow-up. Video available at: https://www.jtcvs.org/article/S2666-2507 (21)00299-6/fulltext. any device related complications and remains active on the heart transplant wait list.

\section{DISCUSSION}

Ideally, the inflow cannula should reside in the central portion of LV, away from the obstructing surfaces and oriented toward the mitral valve, to reduce chances of flow impairment and suck down events. Severe apical calcification may pose a surgical challenge. ${ }^{1-6}$ Surgical techniques can be categorized as:

- Radical apical decalcification and reconstruction, ${ }^{1,2,4}$ which requires extensive surgery and carries a risk of bleeding. It could also lead to a small LV cavity that may affect the cannula position and long term LVAD function. ${ }^{5}$

- Choosing an alternative site for device insertion; that is, lateral or inferior wall. Lateral wall implantation carries a risk of cannula malposition toward septum. Inferior wall implantation is better suited to low-profile devices like HeartWare HVAD (Medtronic, Minneapolis, Minn) and may not be possible in all cases, especially with restricted pericardial space.

We present a simple technique of applying a gentle distortion force to redirect the inflow cannula after anterolateral wall implantation. After initiation of LVAD flow, the LV wall tension reduces, and compliance improves. In our case, the medial part of the LV wall near the anchoring 

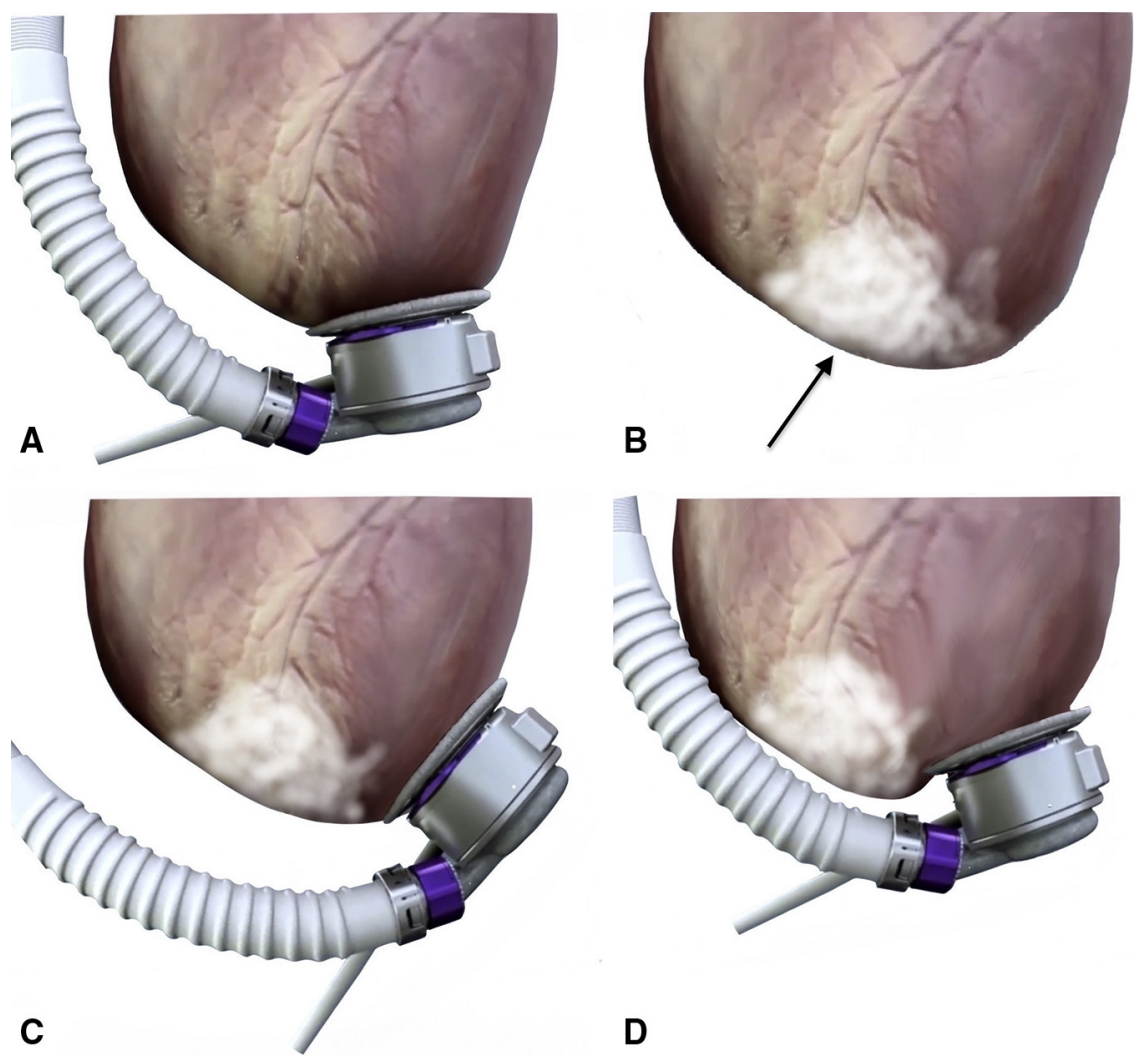

FIGURE 2. Illustration demonstrating gentle distortion of the left ventricle (LV) wall for redirection of inflow cannula. A, Normal insertion site of left ventricular assist device (LVAD) insertion. B, Apical calcification (black arrow) as seen in our case. C, Anterolateral wall insertion of LVAD. D, Illustration of gentle distortion of LV wall after a redirection anchoring suture was placed.

ring was receiving compression force and the lateral part was having tension. Surrounding limited endocardial decalcification ensured adequate LV wall compliance. However, this technique may not be suitable for patients with acute infarct and a friable LV wall.

Three important things must be carefully evaluated:

- Diastolic dimension (width of the cone) Patients with smaller diastolic dimensions usually have higher relative wall thickness that may require excessive distortion force.

- Apex to mitral annular plane distance (length of cone) A short distance between apex and mitral valve leaflets possesses a risk of mitral leaflet ingestion into the cannula.

- Distance of papillary muscle from anticipated coring site Proximity to the papillary muscle may worsen the mitral regurgitation by causing restricted leaflet motion after distortion. Preexisting moderate to severe mitral regurgitation with restricted leaflet motion secondary to LV dilation precludes this technique.

Although inflow cannula positioning can be guided with TEE, a robust 3-dimensional understanding of cardiac anatomy and awareness about surrounding mobile (pericardium) and immobile (ribs) structures are very important for anchoring suture placement. We recommend relaxing the chest wall retractor to anticipate how surrounding structures could move in relation to each other after chest closure and confirming the cannula position after the chest closure, on day 1 , day 3 , and before dismissal. Long-term durability remains unclear.

\section{CONCLUSIONS}

Our technique can be successful in carefully chosen cases.

\section{References}

1. Atluri P, Dymond DJ, Woo YJ. Continuous-flow left ventricular assist device implantation in the presence of a hostile ventricular apex. J Thorac Cardiovasc Surg. 2013;146:981.

2. Bejko J, Tarzia V, Gerosa G, Bottio T. Use of the Jarvik 2000 to facilitate left ventricular assist device placement in challenging apex anatomy. J Heart Lung Transplant. 2016;35:1049-51.

3. Kimura Y, Seguchi O, Kono A, Matsumoto M, Kumai Y, Kuroda K, et al. Massive biventricular myocardial calcification in a patient with fulminant myocarditis requiring ventricular assist device support. Intern Med. 2019;58:1283-6.

4. Palmen M, Verwey HF, Haeck ML, Holman ER, Schalij MJ, Klautz RJ. Implantation of a left ventricular assist device in patients with a complex apical anatomy. Ann Thorac Surg. 2012;94:2122-5.

5. Salas De Armas IA, Akay MH, Patel JA, Patel C, Patel MK, Akkanti B, et al. Implantation of left ventricular assist device in the setting of heavily calcified left ventricular apex using an apex preserving technique. VAD J. 2019;5:2.

6. Soufi MK, Rejjal LA, Schaefer KS, Jackson TR, Roughneen PT, Al-Dossari GA, et al. Rock at the LVAD core: inadvertent calcified apical aneurysm during LVAD Implantation. J Card Fail. 2019;25(8 Suppl):S119-20. 